\title{
Effects of Warning and Information Labels on Attraction to Television Violence in Viewers of Different Ages
}

\author{
BRAD J. BUSHMAN ${ }^{1}$ \\ Institute for Social Research \\ University of Michigan, USA; Vrije Universiteit, Amsterdam, the Netherlands
}

\begin{abstract}
Warning labels on violent television programs give viewers discretionary advice and, therefore, might arouse reactance in viewers of all ages. Information labels give viewers information but no advice and, therefore, should not arouse reactance. Five age groups were tested: 9-11 year olds, 12-14 year olds, 15-17 years olds, 18-20 year olds, and adults at least 21 years old. Participants $(N=900)$ read descriptions of violent and nonviolent TV programs and rated how much they wanted to watch them. The description contained a warning label, an information label, or no label. Consistent with reactance theory, results showed that warning labels drew people of all ages to violent TV programs. Information labels did not draw viewers to violent programs.
\end{abstract}

Since its introduction to American society, television has become an integral part of nearly every home. It is estimated that there are more TV sets in the United States than there are toilets. About $60 \%$ of the programs shown on TV contain violence (National Television Violence Study, 1996, 1997, 1998). Research from numerous studies conducted over several decades - including laboratory experiments, field experiments, cross-sectional studies, and longitudinal studies - shows that TV violence increases societal violence (Anderson \& Bushman, 2002; Bushman \& Anderson, 2001; Bushman \& Huesmann, 2001).

Because of the harmful effects of televised violence on society, it is important to understand what draws viewers to violent TV programs. One possible factor is the use of warning labels and restrictive ratings on violent TV programs. Violent TV programs are identified with warning labels (e.g., "Due to some violent content, viewer discretion is advised"), age-based ratings (e.g., "TV-14: Parents Strongly Cautioned"), or both. These labels could either draw viewers by making violent programs forbidden fruits, or they could repel viewers by making violent programs tainted fruits. The

${ }^{1}$ Correspondence regarding this manuscript should be addressed to Brad J. Bushman, Institute for Social Research, University of Michigan, 426 Thompson Street, Ann Arbor, MI 48106. E-mail: bbushman@umich.edu

2073

Journal of Applied Social Psychology, 2006, 36, 9, pp. 2073-2078.

(C) 2006 Copyright the Authors

Journal compilation (c) 2006 Blackwell Publishing, Inc. 
scientific evidence is most consistent with the forbidden-fruit hypothesis (Bushman \& Cantor, 2003).

One alternative to using warning labels is to use information labels (e.g., "This program contains some violence" or a "V" content code indicating violence). Both types of labels inform viewers that the program contains violence. However, the warning label has an additional component: It gives people advice (whether or not they want it).

It is this additional component that possibly arouses reactance in viewers. Reactance is defined as negative responses to loss of freedom, or to threats of loss (Brehm, 1966). When people lose a desired option, they respond by increasing their desire for that option, by trying to do what is now forbidden, or by aggressing against the person who deprived them of the option.

Bushman and Stack (1996) found that although warning labels attracted college students to violent programs, information labels did not. The present research was conducted to determine whether the findings reported by Bushman and Stack will generalize to other age groups. Although college students might differ from other age groups in some regards, previous research has shown reactance effects in people of all ages, including children as young as 2 years old (Brehm \& Weinraub, 1977).

In the present study, participants ranging in age from 9 to 77 years read descriptions of violent and nonviolent TV programs and rated how much they wanted to watch the programs. The descriptions contained either a warning label (i.e., "This program contains violence. Viewer discretion is advised."), an information label (i.e., "This program contains violence."), or no label. On the basis of reactance theory, warning labels are expected to attract participants of all ages to violent programs. Information labels are not expected to attract viewers to violent programs because they are not expected to induce reactance.

Method

\section{Participants}

Five different age groups were tested: 9-11 year olds, 12-14 year olds, 15-17 year olds, 18-20 year olds (college students), and adults at least 21 years old who were not college students. There were 180 participants (90 males, 90 females) in each age group, for a total of 900 participants.

The children were selected from public schools in central Iowa and were included only if a parent or guardian consented to their participation. The college students were enrolled in Introductory Psychology courses at Iowa State University and received extra course credit in exchange for their voluntary participation. The adults were frequenting public locations 
(e.g., shopping malls) in central Iowa and received a snack in exchange for their voluntary participation. The adults ranged in age from 21 to 77 years ( $M=39$ years, $S D=13$ years).

\section{Procedure}

Participants were told that the study was part of a National Consumer Research Project being conducted to evaluate untitled made-for-television movies that had never been shown in movie theaters or on TV. Participants read descriptions of fictitious, untitled made-for-television films (see Bushman \& Stack, 1996). Half of the descriptions were for violent TV programs, and half were for nonviolent TV programs. By random assignment, the violent program descriptions contained either a warning label (i.e., "This program contains violence. Viewer discretion is advised."), an information label (i.e., "This program contains violence."), or no label (control). The labels were printed in bold, uppercase font and were enclosed in asterisks.

Warning labels were used, rather than age-based ratings, for two reasons. First, warning labels apply to a wider range of ages than do age-based ratings. For example, the warning label "Viewer discretion is advised" applies to viewers of all ages, whereas the age-based rating TV-14 applies only to viewers younger than 14 years. Second, warning labels are easier to interpret than are age-based ratings (Bushman \& Cantor, 2003). Information labels were used rather than content codes (e.g., "V" for violent content) because they are easier to interpret (Bushman \& Cantor, 2003).

The order of the TV program descriptions was counterbalanced according to a Latin square design (see Cochran \& Cox, 1957). Participants rated how much they wanted to watch each program (i.e., "I would like to watch this TV program.") on a 10-point scale ranging from 1 (strongly disagree) to 10 (strongly agree). Next, they reported the number of hours per week they spent watching various types of TV programs, including violent ones. The number of hours per week spent watching violent TV programs was used as a covariate in the analyses to control for habitual exposure to TV violence. Participants also reported their ages. Finally, they were individually debriefed and thanked for their participation.

\section{Results}

\section{Preliminary Analyses}

Effects of labels on ratings of nonviolent TV programs. Although labels were not applied to the nonviolent programs, it is possible that among participants in the label conditions, the labels on the violent programs 
influenced ratings of the nonviolent programs. Analyses reveal that ratings of the nonviolent programs were not influenced by label condition $(p s>.05)$.

Counterbalance order. There were no significant effects involving counterbalance order $(p s>.05)$. Thus, the data from the different orders were combined for subsequent analyses.

\section{Main Analysis}

The data were analyzed using a 3 (Label Condition: warning label, information label, or no label control) $\times 5$ (Participant Age: 9-11 years old, 12-14 years old, 15-17 years old, 18-20 years old, or at least 21 years old) $\times 2$ (Participant Gender) ANCOVA. The covariate was the number of hours per week spent viewing violent TV.

The analysis found a significant effect for label condition, $F(2,869)=$ $6.65, p<.005$ (see Table 1). As expected, participants in the warning label condition wanted to watch the violent TV programs more than did participants in either the information label or the no-label control conditions, $t(869)=2.35, p<.05, d=0.16$; and $t(869)=3.59, p<.05, d=0.24$, respectively. The information and no-label conditions did not differ, $t(869)=1.22$, $p<.3, d=0.08$.

Other significant effects, less central to the hypotheses being tested, also were found. Males wanted to watch the violent TV programs more than did females $(M \mathrm{~s}=6.14$ and 5.70, respectively), $F(1,869)=12.42, p<.0005$, $d=0.24$. There also was a significant effect for age, $F(4,869)=29.56$,

Table 1

Desire to Watch Violent Television Programs for Various Label Conditions

\begin{tabular}{lcc}
\hline Label condition & $M$ & $S E$ \\
\hline Warning label & $6.21_{\mathrm{a}}$ & .105 \\
Information label & $5.86_{\mathrm{b}}$ & .105 \\
No-label control & $5.68_{\mathrm{b}}$ & .104 \\
\hline
\end{tabular}

Note. $n=300$ (150 males, 150 females) per label condition. Total $N=900$. Means were adjusted for habitual exposure to television violence. Means having the same subscript are not significantly different at the .05 level. Tukey's honestly significant difference (HSD) test was used to control both experimentwise and comparisonwise Type I error rates. 
Table 2

Desire to Watch Violent Television Programs for Various Age Groups

\begin{tabular}{lcc}
\hline Age group & $M$ & $S E$ \\
\hline $9-11$ years & $6.60_{\mathrm{a}}$ & .135 \\
12-14 years & $6.17_{\mathrm{a}}$ & .139 \\
15-17 years & $6.50_{\mathrm{a}}$ & .138 \\
$18-20$ years & $5.51_{\mathrm{b}}$ & .133 \\
$\geq 21$ years & $4.82_{\mathrm{c}}$ & .136 \\
\hline
\end{tabular}

Note. $n=180$ (90 males, 90 females) per age group. Total $N=900$. Means were adjusted for habitual exposure to television violence. Means having the same subscript are not significantly different at the .05 level. Tukey's HSD test was used to control both experimentwise and comparisonwise Type I error rates.

$p<.0001$ (see Table 2). Children under 18 years old expressed the greatest interest in viewing the violent programs, followed by college students 18-20 years old, followed by adults over 21 years old.

The covariate also was related significantly to participants' desire to watch the violent programs. The more time participants spent watching televised violence, the more they wanted to watch the violent programs, $F(1,869)=37.20, p<.05(r=.27)$. The $R^{2}$ for the full model was .23 .

\section{Discussion}

In the present study, warning labels attracted viewers of all ages (9 to 77 years old) to violent TV programs. Regardless of their age, it seems that viewers consider warning labels to be a restriction on their freedom to watch what they want. These findings suggest that warning labels make violent programs forbidden fruits for people of all ages.

Information labels did not increase attraction to violent TV programs. This finding is important because it suggests that one can inform audience members about programs that contain violence without increasing their desire to watch violent programs. These results are relevant to debates not only over television ratings, but also over ratings for Web sites, videogames, and other types of media. In summary, warning labels might contribute to societal violence by attracting viewers to violent programs. This is a troubling effect of warning labels. 


\section{References}

Anderson, C. A., \& Bushman, B. J. (2002). Media violence and societal violence. Science, 295, 2377-2378.

Brehm, J. W. (1966). A theory of psychological reactance. New York: Academic Press.

Brehm, S. S., \& Weinraub, M. (1977). Physical barriers and psychological reactance: 2-year-olds' responses to threats to freedom. Journal of Personality and Social Psychology, 35, 830-836.

Bushman, B. J., \& Anderson, C. A. (2001). Media violence and the American public: Scientific facts versus media misinformation. American Psychologist, 56, 477-489.

Bushman, B. J., \& Cantor, J. (2003). Media ratings for violence and sex: Implications for policy makers and parents. American Psychologist, 58, 130-141.

Bushman, B. J., \& Huesmann, L. R. (2001). Effects of televised violence on aggression. In D. G. Singer \& J. L. Singer (Eds.), Handbook of children and the media (pp. 223-254). Thousand Oaks, CA: Sage.

Bushman, B. J., \& Stack, A. D. (1996). Forbidden fruit versus tainted fruit: Effects of warning labels on attraction to television violence. Journal of Experimental Psychology: Applied, 2, 207-226.

Cochran, W. G., \& Cox, G. M. (1957). Experimental designs (2nd ed.). New York: Wiley.

National Television Violence Study. (1996). National Television Violence Study (Vol. 1). Thousand Oaks, CA: Sage.

National Television Violence Study. (1997). National Television Violence Study (Vol. 2). Studio City, CA: Mediascope.

National Television Violence Study. (1998). National Television Violence Study (Vol. 3). Santa Barbara, CA: Center for Communication and Social Policy, University of California, Santa Barbara. 